\title{
Study of Development Strategy on Internationalization of Xi'an City Wall Marathon
}

\author{
Hongqiang Li \\ Xi'an Physical Education University , Xi'an 710068 , China \\ lihongqiangpaper@yeah.net
}

Keywords: Xi'an City Wall Marathon; internationalization; influencing factors

Abstract. In order to improve the international level of Xi'an City Wall Marathon, The study analyzes the influencing factors of the operation of 2012 Xi'an Wall Marathon by using the method of literature analysis, questionnaire and mathematical statistics. By finding out the distance that influences the internationalization development of Xi'an Wall Marathon, the study has proposed the some countermeasures, so as to provide a theoretical basis for the internationalization development of Xi'an City Wall Marathon.

\section{Introduction}

With the development of China's economy and the improvement of people's living standard, the marathon races are increasingly held in the cities on mainland China. Xi'an City Wall Marathon race is held on the ancient city wall of Xi'an, which is a unique event in the world. Due to its distinctive features, it was named the "Gold Medal National Sports Tourism Project" and one of the " Ten Charming Festivals in Shaanxi Province" by the State General Administration of Sports and the National Tourism Bureau[1]. The Xi'an City Wall Marathon has already been successfully hosted for 18 times, but the Committee of Xi'an City Wall Marathon has not applied for a domestic marathon event rating from the Chinese Track and Field Association, because it has not reached the corresponding level as stipulated in the domestic marathon events assessment rules. Xi'an City Wall Marathon now has the following main problems: imperfection of games settings; small scale; low level foreign competitors; imperfection of event record system; lack of entertainment and appreciation; imperfection of overall service; imperfection of news media services. Therefore, to determine the distance between the Xi'an City Wall Marathon and the famous international marathons and to find out the solutions to solve the problem are the key issues to promote the internationalization of Xi'an City Wall Marathon.

\section{Method}

This research is focused on the Xi'an City Wall Marathon. The research methods include: Literature analysis, comparative analysis, observation method, questionnaire survey, and mathematical statistics.

We searched the marathon related literature through CNKI, Chinese journal full text database, China excellent papers for master and doctor degree, Baidu, Google and some other means to provide references for this study.

In this paper, we comparatively analyzed some data and related information of the Xi'an City Wall Marathon and other well-known marathons in Beijing, Yangzhou, Xiamen to find out the advantages and disadvantages of the operation of Xi'an City Wall Marathon.

During the 18th Xi'an City Wall Marathon in 2012, we got on the city wall as audience to do field investigation and record of the events in order to obtain detailed information.

We handed out 200 questionnaires to athletes who were in four groups of $5 \mathrm{~km}$ running, 2 groups of $13.7 \mathrm{~km}$ running, one group of 60 meters family partnership running and one group of 13.7 kilometers county cadres relay running. Each group got 27 questionnaires and the total number was 
216 among which 200 were answered and returned with a recovery rate of 92.59\%, 196 were valid questionnaires with an effective recovery rate of $90.74 \%$.

Validity test: after the design of the questionnaire, 14 relevant experts were invited to carry out the content validity test, and $90 \%$ of the experts believed that in line with the requirements of the study, the content of the questionnaire was completely effective.

Reliability test: We used the retest method and chose 20 runners, who participated in the 2011 Xi'an City Wall Marathon, from Xi'an Physical Education University, Northwestern Polytechnical University, and Xi'an Institute of Posts and Telecommunications to answer questionnaires. The interval of the data reliability test was two weeks, and the weighted concordance rate was $91.32 \%$ which was in accordance with the statistical requirements for the reliability test.

We used Excel 2003 to describe the collected data, and enrich the arguments to form the view point of this study.

\section{Results and Analysis}

1. Analysis on the influencing factors of the internationalization development of Xi'an City Wall Marathon

The development scale of Xi'an City Wall Marathon mainly depends on the host operation of the event, and the operation effects of the sports event are affected by many factors.

The operation of sports events refers to that the organizers of the sports events, through the exercise of its functions, use and allocates the input resources of the event, effectively manage and provide game products and services, to achieve the purpose of events process. The factors of sports event operation can be divided into nine aspects: the event attributions, human resources, logistics, information communication, budget control, marketing, competition organization, risk laws, event evaluation. With the consideration of the past experience of Xi'an City wall Marathon, according to the classification of major sports events operation and experts' opinions, the factors that affect the international development of Xi'an City Wall Marathon can be divided into six types including the marathon competition organization, human resources, logistics, capital control, media and other factors. By referring to the literature of the basic elements of large scale events operation, the actual situation of Xi'an City Wall Marathon operation in recent years, and the expert answered questionnaires, 23 factors were identified to affect the development of Xi'an City Wall Marathon. (See Table 1)

Table 1 Influencing factors of the development of Xi'an CityWall Marathon

\begin{tabular}{lllll}
\hline First Level & \multicolumn{3}{l}{ Second Level } & \\
\hline Organization & Schedule & Race route & Athletes & Referee \\
& Awards & Audience & Atmosphere & Appreciation \\
Human resources & Personnel & Talent introduction & Mass basis \\
Logistic service & Medical & Service level & Safety & \\
Capital control & Sources & Bonus & Registration fee \\
Media publicity & TV & Internet & Printed media & Outdoor publicity \\
Others & Cooperation & Marathon culture & \\
\hline
\end{tabular}

2. Analysis of the international development strategy of Xi'an City Wall Marathon

2.1 Full marathon race need to be added to improve international competitiveness

$42.195 \mathrm{~km}$ marathon is the origin of the marathon races and the embodiment of the spirit of marathon. In honor of the Greek messenger Phidippides, the distance of 42.195 kilometers has become a flag to guide the direction of human progress. Marathon has not only brought the world a competition, but also a valuable spiritual wealth. Therefore, in all famous domestic and international marathon races, $42.195 \mathrm{~km}$ race is taken as the main event often with high bonuses to motivate those excellent marathon runners who have the courage to challenge the limit. 
To be truly international, Xi'an City Wall Marathon needs to add the $42.195 \mathrm{~km}$ marathon as one of the races. The full marathon race was added on the agenda of discussion for Xi'an City Wall Marathon in 2010, but has not been finalized until now. The main dispute is the site selection. A view holds that the full marathon race should be held on the wall on the second day of the tournament, while another view holds that it should be held under the wall as a road race. The contradiction of the two views is concentrated in the urban traffic congestion and tournament fees.

However, from the point of view of the internationalization of Xi'an City Wall Marathon, the setting of $42.195 \mathrm{~km}$ marathon not only need to attract domestic and international marathon enthusiasts to participate, but also to attract internationally renowned marathon runners to join the race, so as to improve the record of the full marathon race and to make both the athletes participating scale and the scores of Xi'an City Wall Marathon reach the international level. From this perspective, the selection of Xi'an marathon site can take reference from the standards of international marathon races. The International Marathon has norms of the hardness of the race tracks which must be hard ground, such as asphalt and even the floor board but not cement or stone floor, in order to protect competitors of the knee joint. Sand road or grassland is also not used and, in large scale marathon races, no deceleration belt or spike can be found on the road. Therefore, the cement brick road on the City Wall is not the best place to hold the marathon race and the Xi'an marathon should change its site to road or street when it adds the full marathon race. In addition, the full distance road marathon race will be more conducive to expand the Xi'an marathon scale, because the 2012 match on the wall set a limitation of 300 people for each individual race, in order to protect the ancient city wall. This is an objective problem in the expanding of competition scale in the internationalization process of Xi'an City Wall marathon.

2.2 Improvement of incentives to attract high-level talents

For the international development, Xi'an City Wall Marathon need to attract more talents with international influence, so as to promote the internationalization trend of Xi'an City Wall Marathon. The talent introduction includes the introduction of the players, referees, guests, media reporters and other staff.

However, from the 18 marathon events that have been successfully held, except some invited guests with international influence, the invitation of high-level athletes, referees and media reporters is not good enough. Athletes basically applied to join the marathon competition individually, and the results were not up to the level of international competition. The organizing committee did not specifically invite some professional marathon athletes to join the competition. The referees were all local referees elected by the Xi'an Municipal Sports Bureau, and there were almost no excellent referee from other provinces. The media reporters who reported the marathon race were consigned by local media, and the organizing committee did not invite any famous reporters to visit the site.

The introduction of high level talents is necessarily related with the salary or payments provided by the committee and the introduction of high level Marathon runners is related with the tournament bonus. The introduction of well-known referees and media reporter is also inevitably correlated with labor costs. The invitation of guests with international influence also needs to have certain incentives or souvenirs as a rebate. In 2012, Xi'an City Wall Marathon was totally invested 80 million RMB Yuan while Beijing and Xiamen International Marathon provided the first prize of full marathon 30,000-40,000 U.S. dollars [2,3,4]. It is not realistic for Xi'an to set such high bonuses to attract international high level athletes for its half marathon; Xi'an Marathon Committee gave reporters liaisons 100 RMB Yuan for allowance and 300-500 RMB Yuan for subsidies to the media reporters. In view of this, it is difficult to improve the salary greatly, but the committee can develop the winning trophies, medals, certificates, souvenirs, product spokesperson etc. through sponsor channels to attract more high-level talents and to promote the international development of Xi'an City Wall Marathon.

2.3 To provide electronic chip service and record the results of all participating athletes

In the investigation, $91.84 \%$ players were willing to get certificates or proofs marked with the results of their own race. (See Table 2) But in Xi'an City Wall Marathon, a lot of players are unable to obtain their accurate performance results in the race. In the domestic well-known marathons, almost all 
the scores of contestants can be published. Therefore, Xi'an City Wall Marathon should change its manual timing to the chip timing and publish not only the top eight players in the performance but all player that complete the tournament sport within a prescribed time.

Table 2 The athletes who want to obtain the certificate of competition performance ( $n=196)$

\begin{tabular}{lcccccc}
\hline \multicolumn{2}{c}{ Very willing } & Willing & Common & Not too willing & Unwilling & \\
\hline Number & 180 & 9 & 7 & 0 & 0 \\
Percentage $(\%)$ & 91.84 & 4.59 & 3.57 & - & - \\
\hline
\end{tabular}

When the Committee use electronic timing chips, because the route of marathon race is long, supervising jurisdiction and security personnel are on duty at intervals. In order to avoid unfairness, in addition to the induction bands arranged at the start and end time, timing chip induction should be set along the race route on designated locations or reentry point, and in monitors should be set on each induction band so as to record video of players. Once complained, it can be verified through surveillance video. Only in this way can ensure the fairness of the long distance events.

The committee cannot ask players to buy chips when it provides electronic chip services because the electronic timing chips can be recycled. The best way is rental service, which can reduce the costs of athletes and will be more readily accepted. It would be better to clearly define the chip service requirement in the marathon competition rules. The committee provides chip timing service for all athletes participated in the half marathon, $5 \mathrm{~km}$ and 13.7 kilometers race; timing chips can be issued with the athletes number before the game and players can be required to pay a certain amount of deposit, which will be returned to the athletes at the end of the game when players return the chip at the specified location. If the chip is lost or damaged, the deposit will not be refunded.

2.4 To improve the star effect and enhance the ornamental tournament

The expanding of the scale, improvement of the performance and enhancement of the star effect all can improve the ornamentation of the competition. But according to the operation status of the Xi'an City Wall Marathon, only improving the star effect is the most effective measure to improve the ornamentation.

The Xi'an City Wall Marathon is relatively small compared to other domestic marathon races. Because of the restrictions from the cultural relics of the venue, all projects and the number of visitors are restricted. For example, $5 \mathrm{~km}, 13.7$ kilometers and the half race of Xi'an City Wall Marathon are limited to 300 participants, and there were only 8000 people on the city wall in 2012.

In Xi'an City Wall Marathon race performance, foreign athletes were not better than Chinese athletes; and the performance of the top 8 runners in the half race of Xi'an City Wall Marathon were not better than performance of the top 8 runners in the marathon races of other cities as shown in Table 3 [5]. The top 8 runners in the half marathon races of other cities marathon were basically foreign athletes invited by their committees. Therefore, from the current perspective, Xi'an City Wall Marathon can only rely on the introduction of foreign outstanding marathon athletes to achieve the higher international level in terms of performance.

Table 3 Half marathon performance of Xi' an and Yangzhou in 2012

\begin{tabular}{llllllll}
\hline Xi'an & & & \multicolumn{5}{c}{ Yangzhou } \\
Gender & Rank & Result & Nationality & Gender & Rank & Result & Nationality \\
\hline Male & 1 & $1: 10: 37$ & Chinese & Male & 11 & $1: 10: 25$ & Kenyan \\
Male & 8 & $1: 21: 52$ & Chinese & Male & 38 & $1: 22: 39$ & Chinese \\
Female & 1 & $1: 15: 27$ & Chinese & Female & 16 & $1: 16: 03$ & Chinese \\
Female & 8 & $1: 25: 13$ & Norwegian & Female & 54 & $1: 25: 19$ & Chinese \\
\hline
\end{tabular}

Previous Xi'an City Wall Marathons confined the star effect to invitation of sports stars, foreign and native politicians and some well-known leaders of large enterprises to be guests or lead the running. This way can undoubtedly attract come audience, but it cannot closely connect these stars or celebrities and the contestants and the audience. If these sports stars and celebrities can participate in 
the marathon races, and share the joy and hardships of the long run with other players, it will undoubtedly improve the ornamentation of the event.

Therefore, the measures to improve the star effect of Xi'an City Wall Marathon can include: first, the introduction of sports stars to participate in the competition as a competitor; second, the introduction of other field stars to participate in the marathon to take full advantage of their star effect, so as to improve the ornamentation of the tournament; third, to attract non stardom people who has a certain influence on the society to take part in the game. For example, Xi'an has many colleges and universities gathered here, the heads of the College Physical Education Group (Department) or primary and secondary school sports team can form a team to participate in the marathon, which can be propaganda of the Wall Marathon race in schools and an improvement of the ornamentation.

2.5 Each department coordinate and cooperate together to improve the service level.

In 2012, the contestants dissatisfaction of Xi'an City Wall Marathon was mainly focused on the number of mobile toilets, certificate of achievement, storage of articles and packets, water drinking points, too little audience, puzzle of signs, medical station, and the car services. These issues need to be resolved in order to improve the overall service level of the tournament, which requires the coordination and cooperation between the event organizers and the various departments.

According to the operation of the Xi'an city wall marathon event, to solve the service vulnerabilities and improve the effectiveness of existing operations, a special committee can be set up to manage the big events. Xi'an City Wall Marathon Organizing Committee should have at least ten branches, namely the Office, Committee of the Competition, Athletes Commission, Committee of Personnel Enrollment, Security and Traffic Committee, Media and Publicity Committee, Medical Council, Volunteer Committee, Sponsors Services Committee and Integrated Services Committee.

The work of the Office is mainly to assist the Organizing Committee to coordinate the work of the Committee and to be responsible for the relevant matters of the organizing committee. The Competition Committee is mainly responsible for organizing and implementing the Xi'an City Wall Marathon race in the preparation period, competition period and the end of the competition. Athletes Committee is mainly responsible for the athletes' registration, qualification and scheduling, and other work to coordinate the Volunteer Committee to do a good job of volunteer work. Committee of Personnel Enrollment is mainly responsible for the work to attract professional marathon athletes, sports stars, referees, well-known media reporters, and other introduction of human resource. Security Committee is mainly responsible for the safety and security work, and the other work distributed by the organizing committee. Media and Publicity Committee is mainly responsible for print media, network media and television media coverage of the work of publicity and services. The Medical Council is mainly responsible for the emergency work during the event and the volunteer medical training work [6]. Volunteer Committee is mainly responsible for organizing the training and management of volunteer teams. Sponsor Services Committee is mainly responsible for the implementation of the rights and interests of sponsors, to assist in the approval of the advertising along the marathon route. Integrated Services Committee is mainly responsible for the storage of players clothing and articles, mobile toilets, drinking water and energy supply points, etc [7].

2.6 To improve the media service system and expand the media publicity effect

In the reports of Xi'an city wall international marathon race, media need to make full use of their advantages with their own characteristics to improve the team cooperation ability. They can show their own style and enhance exchanges within the industry, and provide multi angle information of the sports to fully meet the needs of various audiences.

2.6.1 Xi'an City Wall Marathon official website

Firstly, Xi'an City Wall Marathon needs to establish English official website. The internationalization development of Xi'an City Wall Marathon is bound to attract more foreign athletes and foreign audience. Therefore, Xi'an City Wall Marathon should set up English official website for foreign audience to know more about the Xi'an marathon.

Secondly, the official website should be kept open throughout the year; the official website of the Xi'an City Wall Marathon is now open only from the start of online registration until one month after 
the end of the game. In this way, it is difficult for many people to get accurate information about the Xi'an City Wall Marathon in the first time.

Thirdly, the official website needs to use new media like micro-blog, blog and forums to provide more, faster and more extensive information for the media workers. This can also bring huge advertising profits for new media operators, and thus promote the relevant media to join the publicity of the event. Micro blog, blog and forum on the official website will increase the direct interaction between the public and can be directly supervised by the media. This open attitude will certainly be generally welcomed. Famous persons' sharing of their feelings and experiences in the game will attract more fans to know the charm of marathon and Xi'an.

2.6.2 Introduction of various types of foreign media

Every time, Xi'an City Wall Marathons have invited dignitaries from friend cities to be guests. As an opportunity, it can also invite some media from friend cities to report Xi'an City Wall Marathon, and let more foreign people to understand the Xi'an City Wall Marathon. The propaganda effect will be better.

2.6.3 To provide perfect service measures to the media

In order to ensure the smooth work of the various types of media, in addition to the basic media services, such as the announcement of overall situation, accommodation, transportation and catering, special liaison, photograph and interview sites, and the issue of subsidiary allowance through a press conference, the Organizing Committee also needs to strengthen the medical security of media staff, to provide media services such as professional volunteers and language services.

\section{Conclusion}

Xi'an City Wall Marathon needs to set full marathon project under the city wall, and shift to an earlier date; introduce high-level talents and improve the level of internationalization by improving the event bonus, set the trophy, gift souvenirs, and other incentives; provide electronic chip timing service to ensure the fairness of the results; improve sports and non sports star effects to enhance the ornamentation; establish organizing committee and adopt functional management and various functional departments need to work in the scope of its own functions which will be more conducive to increase the efficiency of information transmission. But all departments also need to coordinate and cooperate with each other to improve the service system of the whole event. The marathon official website needs to be opened and updated all the time and an English website is needed. Micro blogging, blog, forums and other new media should be adopted to meet the needs of different audience.

\section{References}

[1] Information on http://www. xamls.cn

[2] Information on http://www. bei jing-marathon.com

[3] Jin Yinghua, Yuan Yujie. An Analysis of Social and Economic Benefit of Beijing 2007 International Marathon. Journal of Beijing Sport University. Vol. 31 (2008)

[4] Li Zifei. City Government's Public Service Supply Innovation -- Experience and Enlightenment of the Operation Mode of Xiamen International Marathon. Dissertation of Xiamen University, (2005)

[5] Huang Chenghua. Study on the Current Situation and Development of Jianzhen International Half Marathon Yangzhou, Jiangsu Province. Dissertation of Yangzhou University, (2010)

[6] Zhang Lixin. Medical Support Model and Practice for International Marathon Game. Hospital Administration Journal of Chinese People's Liberation Army. Vol. 18 (2011), p.462

[7] Ding Yi. Current Situation of Marketing of Shanghai International Marathon and Its' Countermeasures. Journal of Chengdu Sport University. Vol. 30 (2004) 